\title{
ARTICLE \\ Homeostatic cAMP regulation by the RGS7 complex controls depression-related behaviors
}

\author{
Cesare Orlandi $\mathbb{D}^{1}$, Laurie P. Sutton $\mathbb{D}^{1}{ }^{1}$, Brian S. Muntean ${ }^{1}$, Chenghui Song ${ }^{1}$ and Kirill A. Martemyanov ${ }^{1}$
}

\begin{abstract}
Affective disorders arise from abnormal responses of the brain to prolonged exposure to challenging environmental stimuli. Recent work identified the orphan receptor GPR158 as a molecular link between chronic stress and depression. Here we reveal a noncanonical mechanism by which GPR158 exerts its effects on stress-induced depression by the complex formation with Regulator of G protein Signaling 7 (RGS7). Chronic stress promotes membrane recruitment of RGS7 via GPR158 in the medial prefrontal cortex (mPFC). The resultant complex suppresses homeostatic regulation of cAMP by inhibitory GPCRs in the region. Accordingly, RGS7 loss in mice induces an antidepressant-like phenotype and resiliency to stress, whereas its restoration within the $\mathrm{mPFC}$ is sufficient to rescue this phenotype in a GPR158-dependent way. These findings mechanistically link the unusual orphan receptor-RGS complex to a major stress mediator, the cAMP system and suggest new avenues for pharmacological interventions in affective disorders.
\end{abstract}

Neuropsychopharmacology (2019) 44:642-653; https://doi.org/10.1038/s41386-018-0238-y

\section{INTRODUCTION}

Affective disorders are a major source of disability causing substantial health and socioeconomic burden. It has been well established that the medial prefrontal cortex (mPFC) is involved in emotional responses and mood regulation and that disruption within this circuit can cause affective disorders, such as anxiety and depression [1, 2]. Clinical and preclinical studies show that anxiety and depression are associated with synaptic deficits in the mPFC, while interventions within this region induce therapeutic effects [3-5]. Similarly, animal models of stress-induced depression display synaptic loss on the pyramidal neurons of the MPFC, which is associated with depression-like phenotypes [6-10]. While both genetic and environmental factors contribute to the maladaptive responses, stress is one of the most prevalent factors, which can precipitate or exacerbate affective disorders [11-13].

Antidepressant drugs, the current pharmaceutical interventions for depression, produce their therapeutic effects by direct or indirect targeting of neuromodulatory systems that engage $\mathrm{G}$ protein-coupled receptors (GPCR) [14-18]. Although the pharmacological effects of these drugs are immediate, the therapeutic efficacy is delayed from weeks to months with a population of patients that do not adequately respond to treatment at all [17, $19,20]$. Limitations in efficacy are largely attributed to an insufficient understanding of neuronal circuitry and GPCR signaling cascades involved in modulating mood and stress responses.

One of the central signaling systems involved in controlling adaptive cellular responses is the second messenger cAMP [21]. Upregulation of CAMP levels has been suggested to contribute to an antidepressant-like phenotype after stress exposure in mice, whereas inhibiting CAMP signaling often induces maladaptive behavioral response $[22,23]$. Similar changes have been described in the brains of patients affected by major depressive disorder
(MDD) $[24,25]$. The production of cAMP is controlled by many neurotransmitter GPCRs that signal via Gs or Gi to either stimulate or inhibit cAMP synthesis by adenylate cyclases (ACs), respectively [21]. Notably, signaling via several GPCRs has been implicated in the pathophysiology of MDD, as well as the effects of stress and the pharmacological modulation of monoamine GPCRs is a mainstay practice in treating MDD $[15,26]$.

In an effort to identify novel targets for intervention in MDD, a screen for abundant stress-regulated receptors in the PFC identified the novel orphan GPCR, GPR158 as a key modulator of stress-induced depression. Increased levels of GPR158 have been observed in the dorsolateral PFC of MDD patients and following chronic stress in the MPFC of mice. Conversely, ablation of GPR158 in mice produced an antidepressant-like effect and resiliency to stress-induced depression. Intriguingly, manipulations with GPR158 influenced intracellular CAMP content, suggesting that this orphan receptor is engaged in signaling reactions relevant to mood regulation. Proteomic screens previously identified GPR158 as a binding partner of Regulator of $G$ protein Signaling 7 (RGS7) protein, a brain-enriched potent negative modulator of $\mathrm{G}_{\mathrm{i} / \mathrm{o}}$ signaling. Subsequent studies have shown that GPR158 facilitates the recruitment of RGS7 to the plasma membrane and augments its ability to deactivate $G_{i / o}$ signaling $[27,28]$. More recently, GPR158 has been proposed to also signal via $G_{q}$ in a capacity of a conventional GPCR [29]. However, the signaling mechanisms adopted by this receptor and their relevance to stress-induced depression remain unknown.

Here we decipher the signaling mechanism responsible for GPR158's ability to mediate stress-induced depression. We report that rather than the conventional activation of heterotrimeric $\mathrm{G}$ proteins, GPR158 mediates its effects via RGS7 recruitment to control key cellular nodes associated with affective states and

${ }^{1}$ Department of Neuroscience, The Scripps Research Institute, 130 Scripps Way, Jupiter, FL 33458, USA

Correspondence: Kirill A. Martemyanov (kirill@scripps.edu)

These authors contributed equally: Cesare Orlandi, Laurie P. Sutton.

Received: 17 August 2018 Revised: 25 September 2018 Accepted: 2 October 2018

Published online: 11 October 2018 
delineate the mechanism by which the GPR158-RGS7 complex influences CAMP signaling in the MPFC.

\section{MATERIALS AND METHODS}

Animal models

All studies were carried out in accordance with the National Institute of Health guidelines and were granted formal approval by the Institutional Animal Care and Use Committee. The Gpr158 ${ }^{-1}$ mice were purchased from Knockout Mouse Project (KOMP) repository (Gpr158 $\left.{ }^{\mathrm{tm} 1(\mathrm{KOMP}) \mathrm{Vlcg}}\right)$. Previously published $\mathrm{Rgs} 7^{-/-}$and Rgs $7^{\text {loxP/loxP }}$ mice $[27,30]$ were donated by the investigators. C57BI/6J mice were used in biochemical and behavioral experiments using stress-induced paradigms described below. Mice were housed in groups (unless otherwise stated) on a 12-h lightdark cycle (lights on at 7:00 a.m.) with food and water available ad libitum. Both male and female mice were used to assess emotionality. Male mice were used in all other behavioral assays, while both male and female were used for biochemistry analysis and were between 2 and 5 months of age.

Antibodies, western blots, co-immunoprecipitation, and subcellular fractionation

Rabbit antibodies against the intracellular $C$ terminus of mouse GPR158 (GPR158CT), and N terminus of RGS7 (RGS7NT) were previously described [28]. Rabbit anti-G $\beta 1$ was a gift from Dr. Barry Willardson (Brigham Young University, Provo, UT). Rabbit anti-G $\beta 5$ was a gift from Dr. William Simonds (NIDDK, NIH, Bethesda). Mouse anti-GAPDH (Millipore), anti-BActin (SIGMA), and anti-GFP/ Venus (Roche) were purchased.

For western blot analysis, brains were quickly removed from euthanized mice and medial prefrontal cortex was excised with a $3 \mathrm{~mm}$ puncher. Tissues were lysed in ice-cold lysis buffer $(300 \mathrm{mM}$ $\mathrm{NaCl}, 50 \mathrm{mM}$ Tris- $\mathrm{HCl}, \mathrm{pH} 7.4,1 \%$ Triton X-100, and complete protease inhibitor cocktail (Roche Applied Science, Penzberg, Germany)) and phosphatase inhibitor mix (Sigma-Aldrich, St. Louis, MO) by sonication, incubated on a rocker for $30 \mathrm{~min}$ at $4{ }^{\circ} \mathrm{C}$, and cleared by centrifugation at $14000 \times g$ for $15 \mathrm{~min}$. The supernatant was saved and the protein concentration was obtained using Pierce $660 \mathrm{~nm}$ Protein Assay (Thermo Fisher, Waltham, MA). Samples were diluted in $4 \times$ SDS sample buffer and analyzed by SDS-polyacrylamide gel electrophoresis (SDS-PAGE). Researcher was blinded to the genotype/treatment history of the samples.

For immunoprecipitation, mPFC lysates were cleared by centrifugation at $14000 \times g$ for $15 \mathrm{~min}$, and the supernatants were incubated with $20 \mu \mathrm{l}$ of Dynabeads (Invitrogen) and $2 \mu \mathrm{g}$ of antibodies on a rocker at $4{ }^{\circ} \mathrm{C}$ for $1 \mathrm{~h}$. After three washes with icecold immunoprecipitation buffer $(300 \mathrm{mM} \mathrm{NaCl}, 50 \mathrm{mM}$ Tris- $\mathrm{HCl}$ $\mathrm{pH} 7.4,1 \%$ Triton $\mathrm{X}-100$, and complete protease inhibitor cocktail), proteins were eluted with $50 \mu \mathrm{l}$ of $2 \times$ SDS sample buffer and analyzed by SDS-PAGE.

For subcellular fractionation experiments, tissues were homogenized in ice-cold lysis buffer $(150 \mathrm{mM} \mathrm{NaCl}, 50 \mathrm{mM}$ Tris- $\mathrm{HCl}$, $\mathrm{pH} 7.4,1 \mathrm{mM}$ EDTA, $2.5 \mathrm{mM} \mathrm{MgCl}_{2}$, and complete protease inhibitor cocktail (Roche Applied Science, Penzberg, Germany)) by sonication. Lysates were adjusted to the same protein concentration with lysis buffer and equal amounts were subjected to ultracentrifugation $(200000 \times g$ for $30 \mathrm{~min} / 4^{\circ} \mathrm{C}$ ). The supernatant was recovered and designated as cytosolic fraction. The pellet was washed with the lysis buffer and re-sedimented by centrifugation $(200000 \times g$ for 30 $\left.\min / 4^{\circ} \mathrm{C}\right)$. The pellet was then resuspended in Detergent buffer $(300 \mathrm{mM} \mathrm{NaCl}, 50 \mathrm{mM}$ Tris- $\mathrm{HCl}, \mathrm{pH} 7.4,1 \%$ Triton X-100, and complete protease inhibitor cocktail), incubated on a rocker for $30 \mathrm{~min} / 4^{\circ} \mathrm{C}$ and cleared by centrifugation at $14000 \times g$ for 15 min. The supernatant was saved and designated as membrane fraction.
In situ hybridization

The mRNA expression of Rgs7, Gpr158, and R7bp was evaluated with ViewRNA ${ }^{\text {TM }}$ 2-plex In Situ Hybridization Assay (Panomics, Santa Clara, CA) using the following probe sets: Rgs7 (NM_011880; Cat\# VB6-16551); Gpr158 (NM_001004761; Cat\# VB1-11518 and VB6-17048); and R7bp (NM_029879; Cat\# VB6-16884) as previously described [31]. Confocal images of the layer 2/3 of mPFC were acquired at The Light Microscopy Facility, the Max Planck Florida Institute, using a confocal microscope Zeiss LSM 880 Airy Scan (Carl Zeiss; Plan-Apochromat $\times 20 / 0.8$ M27) setting the fluorescence intensity in non-saturating conditions.

\section{Viral-mediated gene transfer}

Adeno-associated virus (AAV) vector 8 containing Cre recombinase under the transcriptional regulation of synapsin 1 (AAV-Cre) were purchased from Vector Biolabs. The gene encoding RGS7 was subcloned into an AAV9 plasmid under the transcriptional regulation of synapsin 1 (AAV-RGS7) and the same backbone without the gene encoding RGS7 was used as the control plasmid (Vector Core Labs). For stereotaxic delivery of AAVs, a Hamilton microsyringe was used. A rate of delivery was set at $0.1 \mu \mathrm{l} / \mathrm{min}$ with an injection volume of $0.5 \mu \mathrm{l} / \mathrm{site}$ and the injectors were kept in place for an additional $5 \mathrm{~min}$ to ensure adequate diffusion from the injector tips. The stereotaxic coordinates for targeting the prelimbic area were as follows (rostral to bregma): anteroposterior, $+2.10 \mathrm{~mm}$; mediolateral, $\pm 0.33 \mathrm{~mm}$, dorsoventral, $-1.50 \mathrm{~mm}$.

\section{Drug treatments}

Yohimbine, WAY100635, and raclopride were purchased from Tocris (Bristol, UKingdom)), while naloxone and CGP35348 were purchased from Sigma-Aldrich (St. Louis, MO). Mice were injected with saline on three consecutive days before the start of the study to acclimate the animals to the injection procedure. Mice received a single injection of yohimbine $(1 \mathrm{mg} / \mathrm{kg}$, intraperitoneal (i.p.)), WAY100635 (0.1 mg/kg, subcutaneous), CGP35348 (50 mg/kg, i.p.), raclopride (1 $\mathrm{mg} / \mathrm{kg}$, i.p.), naloxone (1 $\mathrm{mg} / \mathrm{kg}$, i.p.), or appropriate vehicle, and $30 \mathrm{~min}$ later were subjected to the behavioral testing. Sub-threshold doses for each drug were chosen as they have been shown to be ineffective in the tail suspension test (TST) and/or forced swim test (FST) [32-37].

Stress models: unpredictable chronic mild stress and physical restraint stress

All animals were age- and weight-matched before commencement of any stress procedures. Unpredictable chronic mild stress (UCMS) paradigm and physical restraint stress (PRS) have been described previously [38]. Briefly, mice undergoing UCMS were subjected to 4 weeks of stressors with two stressors applied within a $24 \mathrm{~h}$ period. Stressors were applied pseudo-randomly and included intermittent bell ( $10 \mathrm{db}, 1 / 10 \mathrm{~s})$, continuous white noise $(4 \mathrm{~h})$, rat odor, cage tilt $\left(45^{\circ}, 4 \mathrm{~h}\right)$, cage shaking (30 min), soiled bedding $(8 \mathrm{~h})$, paired housing (with new partner, $2 \mathrm{~h}$ ), overnight illumination, removal of nesting material $(12 \mathrm{~h})$, placement of novel object in home cage $(3 \mathrm{~h})$, and confinement in a small cage $\left(80 \mathrm{~cm}^{3}, 1 \mathrm{~h}\right)$. No stressors were applied on the day of testing $(18 \mathrm{~h}$ prior to any behavioral testing) to avoid effects of fatigue and acute stress but were applied in between testing days. Mice undergoing PRS were restraint in a plastic tube $(30 \mathrm{~mm}$ diameter $\times 115 \mathrm{~mm}$ length) with holes for ventilation for $2 \mathrm{~h}$ for 14 days. Biochemical analysis was performed using the mPFC of mice isolated $1 \mathrm{~h}$ following the final exposure to stress.

Behavioral tests and analysis of emotionality score

All behavioral experiments were carried out with the experimenter blind to genotype and/or treatment history. For the two-bottle sucrose preference test mice were habituated to water bottles containing $1 \%$ sucrose solution or water for 4 days and the bottles position was counterbalanced between days. On testing day, mice 
were individually housed and water-deprived ( $12 \mathrm{~h}$ ) before two pre-weighed identical bottles of water and sucrose solution were presented for $12 \mathrm{~h}$ (between 7:00 p.m. and 7:00 a.m.). The sucrose preference was calculated by dividing the volume of sucrose solution consumed by the total volume of liquid consumed. Marble Burying, elevated plus maze (EPM), TST, and FST were performed as previously described and conducted during the light cycle (between 7:00 a.m. and 12:00 p.m.) [38]. The behavioral paradigm used to calculate the emotionality score were performed in the following order: marble burying, EPM, TST, and FST. There was a 3-4-day period between behavioral tests to minimize the effects of the previous test. To calculate the emotionality score, we used $z$-scoring methodology to integrate standard measures of anxiety-like and depressive-like behaviors, as previously described [38,39]. Emotionality score was evaluated from the following parameters: marble burying (number of marbles buried), EPM (time spent on open arm and number of entries into the open arm), TST (immobility), and FST (immobility). For each parameter, the $z$-score for every individual animal was calculated using the following formula:

$$
Z=\frac{X-\mu}{\sigma}
$$

where $X$ represents the individual data point, $\mu$ represents the mean of control group, and $\sigma$ represents the standard deviation of the control group. The emotionality score for each individual subject was first averaged within test, and then across each test to ensure equal weighting of all tests.

CAMP measurements and AC activity assay

Prefrontal cortex tissue punches ( $2 \mathrm{~mm}$ ) were flash frozen in liquid nitrogen before homogenization in $20 \mathrm{mM}$ HEPES, $\mathrm{pH} 8.0,1 \mathrm{mM}$ EDTA, $150 \mathrm{mM} \mathrm{NaCl}, 2 \mathrm{mM} \mathrm{MgCl}, 1 \mathrm{mM}$ dithiothreitol, and cOmplete protease inhibitor (Roche, Indianapolis, IN) followed by centrifugation at $2000 \times g$ to clear nuclear debris. Plasma membrane isolation was performed by ultracentrifugation in a Beckman SW28.1 rotor at $25000 \mathrm{rpm}$ for $35 \mathrm{~min}$ over a sucrose gradient $(23 / 43 \%)$. The plasma membrane fraction was collected at the sucrose interface and concentration determined by Pierce $660 \mathrm{~nm}$ Protein Assay Reagent (Thermo Fisher Scientific, Waltham, MA).

Total CAMP was determined by diluting tissue homogenate 1:50 in $0.1 \mathrm{~N} \mathrm{HCl}$ followed by quantification using a competitive CAMP enzyme immunoassay according to the manufacturer's guidelines (Direct cAMP ELISA kit, ENZO Life Sciences, Farmingdale, NY). Prefrontal cortex membranes ( $1 \mu \mathrm{g} /$ reaction) were stimulated as indicated with vehicle or purified Gas-GTPYS for $10 \mathrm{~min}$ at $30^{\circ} \mathrm{C}$ in assay buffer (50 mM HEPES, pH 8.0, 0.6 mM EDTA, pH 7.0, $100 \mu \mathrm{g} /$ $\mathrm{ml}$ bovine serum albumin, $3 \mathrm{mM}$ phosphoenolpyruvate potassium, $10 \mu \mathrm{g} / \mathrm{ml}$ pyruvate kinase, $5 \mathrm{mM} \mathrm{MgCl}, 100 \mu \mathrm{M}$ ATP, $10 \mu \mathrm{M}$ GTP, and $100 \mu \mathrm{M}$ IBMX). Where indicated, membranes were preincubated with $100 \mu \mathrm{M}$ of the cellular G $\beta \gamma$-antagonist GRK2i (Tocris; 3594) for $30 \mathrm{~min}$ at $4{ }^{\circ} \mathrm{C}$. The reactions were quenched by addition of $0.2 \mathrm{~N} \mathrm{HCl}$ followed by CAMP quantification.

\section{Adenylate cyclase superactivation cell-based assay}

Cloning of the full-length constructs for mammalian expression of Flag-AC5 and G 35 was previously described [40, 41]. pCMV5 plasmid encoding $\mathrm{Ga}_{\mathrm{OA}}$ was a gift from $\mathrm{H}$. Itoh (Nara Institute of Science and Technology, Japan). Plasmids encoding GABABR1 and GABABR2 were provided by K. Wickman (University of Minnesota) and mas-GRK3-CT was provided by N.A. Lambert (Medical College of Georgia, Augusta, GA). RGS7, G $31, \mathrm{G} \gamma 2$, and ADRA2A in pcDNA3.1+ were purchased from the Missouri S\&T CDNA Resource Center and pGloSensor ${ }^{\mathrm{TM}}-22 \mathrm{~F}$ reporter from Promega (E2301). All constructs were verified by sequencing. Each assay was performed in triplicate. HEK293T cells cultured in $6 \mathrm{~cm}$ plates were transfected with pGloSensor ${ }^{\mathrm{TM}}-22 \mathrm{~F}$ reporter (Promega; E2301), Flag-AC5, Gao, G $\beta 1$, and $G \gamma 2$, and one of the following GPCRs: ADRA2A, GABAB receptors, with or without RGS7/G $\beta 5$, and mas-GRK3CT. Transfected cells were pretreated with the GPCR agonists indicated in the figure legends $(1 \mu \mathrm{M})$ or vehicle for $24 \mathrm{~h}$. Cells were then resuspended in $\mathrm{CO}_{2}$-independent medium (Life Technologies) supplemented with $10 \%$ fetal bovine serum and containing agonist $(1 \mu \mathrm{M})$ or vehicle and incubated with the substrate GloSensor ${ }^{\mathrm{TM}}$ CAMP Reagent (Promega; E1290) for $2 \mathrm{~h}$ at room temperature. Luminescence measurements were made using a microplate reader (POLARstar Omega; BMG Labtech). All measurements were performed at room temperature. After 2 min, cells were treated with $100 \mu \mathrm{M}$ of the specified GPCR antagonist (Yohimbine or CPG35348) and the luminescence was read every $30 \mathrm{~s}$ over a period of $15 \mathrm{~min}$.

Quantification and statistical analysis

Statistical analysis was performed using GraphPad Prism (Prism6.0, GraphPad, San Diego, California). Student's $t$ test was used to compare means between two groups, and one-way or two-way analysis of variance followed by Tukey's or Bonferroni post hoc tests were used to determine significant differences among multiple groups. Statistical tests were performed two-sided unless stated otherwise. Differences were considered significant if $P<$ 0.05 . All data are expressed as means \pm SEM.

\section{RESULTS}

RGS7 interacts with the orphan receptor GPR158 and modulates depressive-like behaviors

Since RGS7 is an established binding partner for GPR158 we hypothesized that the mood-regulating effects of GPR158 may require its complex formation with RGS7. To test this hypothesis, we started by exploring the relationship between RGS7 and GPR158 in the mPFC. First, we confirmed that GPR158 and RGS7 are co-expressed in the majority of mPFC neurons using in situ hybridization (Fig. 1a). Second, both GPR158 and RGS7 showed identical induction of expression late in postnatal development (Supplementary Figure 1a, b). Third, co-immunoprecipitation experiments confirmed that they are indeed present in a complex in the MPFC (Fig. 1b). Fourth, loss of GPR158 resulted in substantial reduction in RGS7 protein level, suggesting that the interaction between these proteins is required for the stability and high expression level of the complex in the MPFC (Fig. 1c). Finally, RGS7 levels at the plasma membrane are significantly reduced in the mPFC of Gpr158 $8^{-1-}$ mice indicating a role for GPR158 in controlling RGS7 subcellular localization (Fig. 1d).

To begin probing the role of RGS7 in stress responses, we first tested mice lacking Rgs7 $\left(\operatorname{Rgs}^{-/-}\right)$in the stress-induced hyperthermia $(\mathrm{SIH})$ paradigm, a model that reflects the activation of the autonomic nervous system by measuring body temperature in response to mild stress. $R g s 7^{-1-}$ mice had a diminished response to the $\mathrm{SIH}$ compared to their wild-type $\left(\operatorname{Rgs} 7^{+/+}\right)$ littermates without affecting their baseline temperature $\left(R g s 7^{+/+}\right.$ $35.05 \pm 0.20^{\circ} \mathrm{C}$ and $R g s 7^{-1-} 35.19 \pm 0.17^{\circ} \mathrm{C}$ ) indicating an anxiolytic behavior (Fig. 1e). We further explored these initial observations by conducting a battery of tests that evaluate anxiety-like and depressive-like behaviors. In the marble burying test $R g s 7^{-1-}$ mice displayed an anxiolytic-like phenotype as evident by burying fewer marbles (Fig. 1f). In the EPM test $\mathrm{Rgs}^{-1-}$ mice spent more time in the open arm and increased number of crossovers into the open arm (Fig. 1g). Rgs $7^{-1-}$ mice also exhibited a reduced immobility time in the TST (Fig. 1h) and FST (Fig. 1i), indicating an antidepressive-like behavior. Using this standard panel of tests (marble burying, EPM, TST, and FST), we performed a metaanalysis using $z$-scoring methodology to calculate overall "emotionality score" for each individual subject (Fig. 1j). We found that $R g s 7^{-1-}$ mice had a lower emotionality score compared to $R g s 7^{+/+}$ 
a
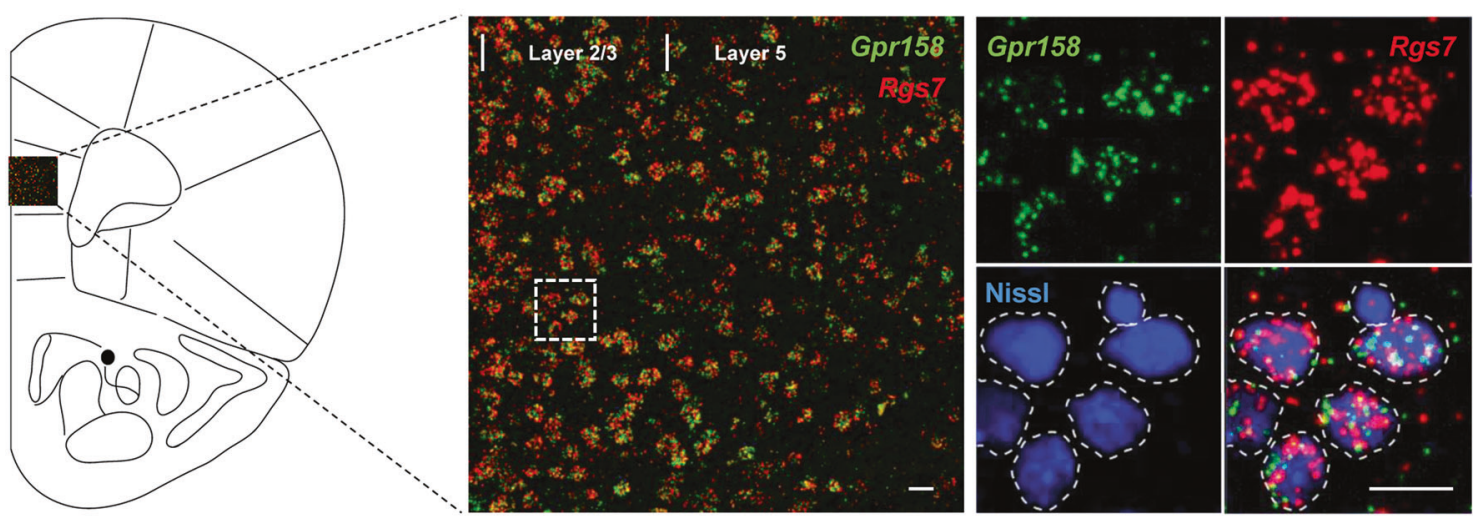

b
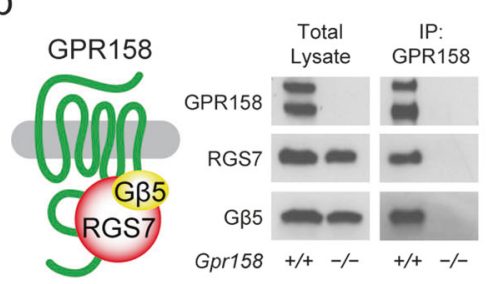

C

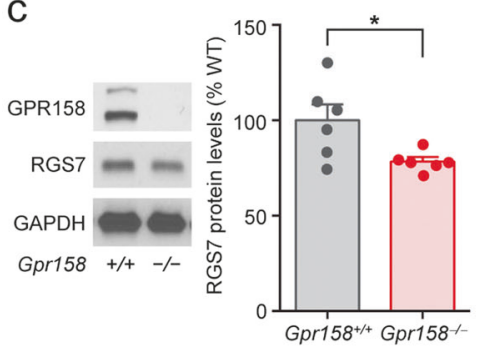

g
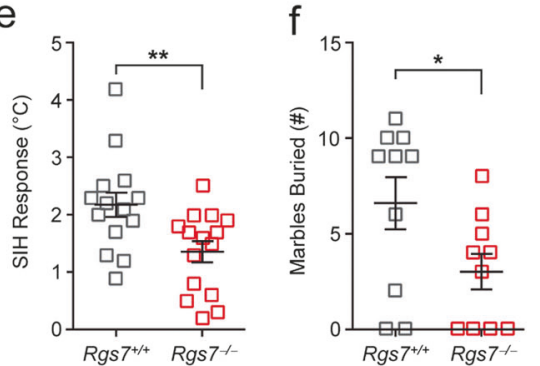

d
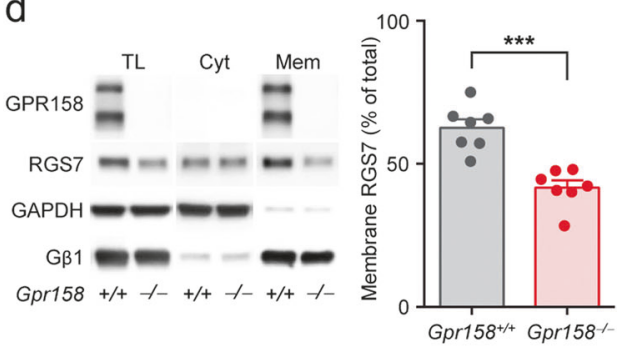
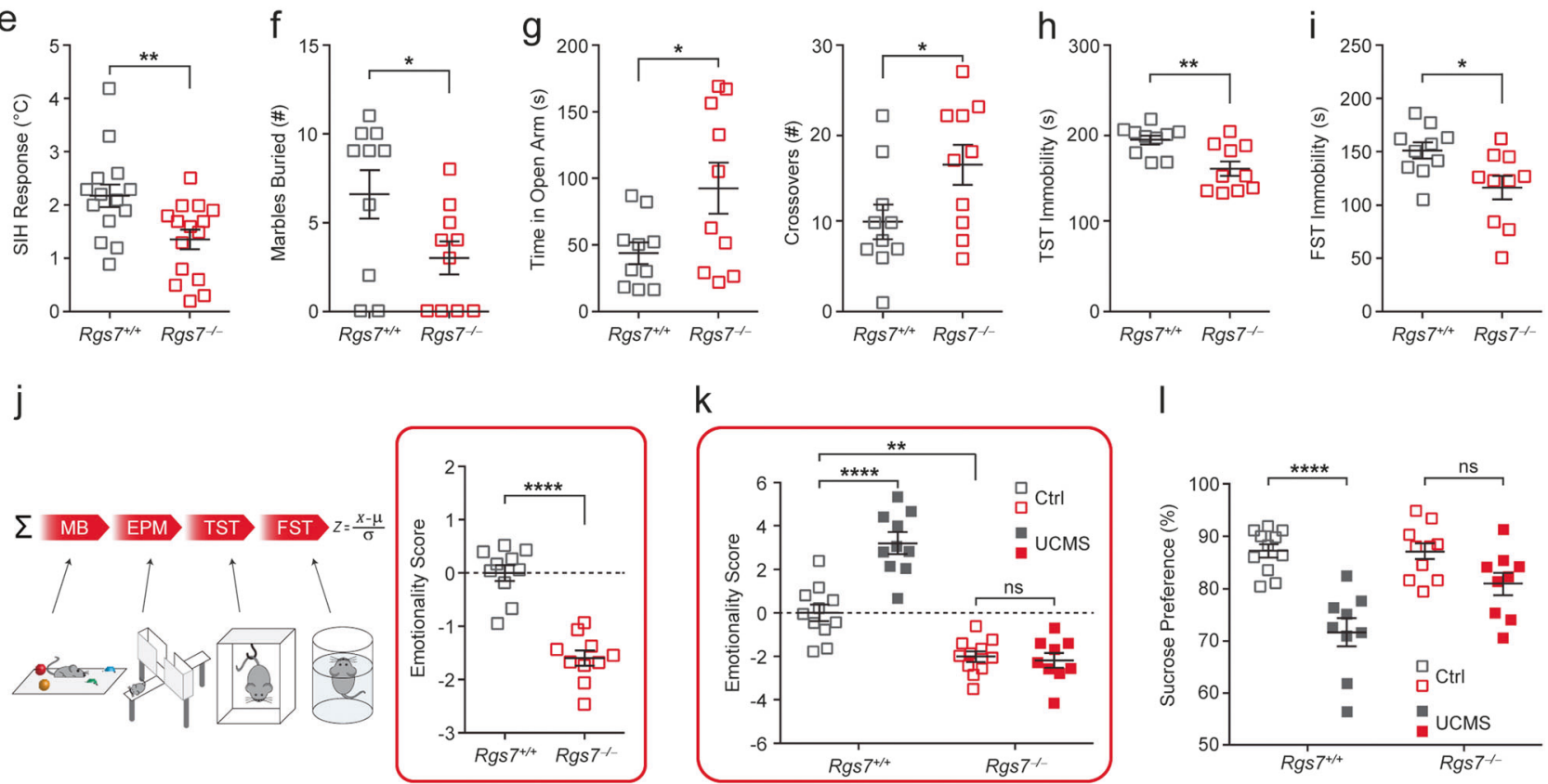

I

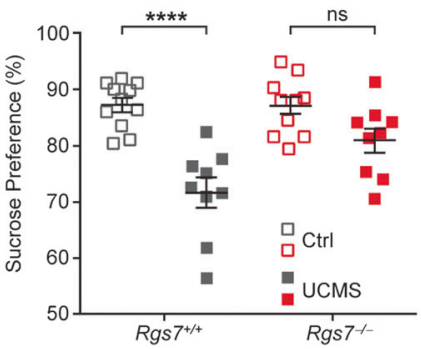

Fig. 1 Ablation of GPR158-binding partner, RGS7, phenocopies effects on stress-induced behaviors. a Representative image of a double in situ hybridization using probes against Rgs7 (red) and Gpr158 (green) in the MPFC. The soma of each cell is identified by Nissl staining (blue) and its boundaries designated by a dashed line (scale bars $=20 \mu \mathrm{m}$ ). b Co-immunoprecipitation of GPR158 with RGS7 from mPFC lysate. Scheme of GPR158 and its binding partner RGS7 (left). c Representative western blot and quantification of RGS7 levels in the mPFC of Gpr158 ${ }^{+/+}$and Gpr158 15 mice $\left(n=6\right.$ mice/genotype; $t_{(10)}=2.553$, Student's $t$ test). d Western blots and quantification of RGS7 levels at the membrane of $\mathrm{Gpr}_{158^{+/+}}$and $\mathrm{Gpr} 158^{-/-}$mice in the MPFC ( $n=7$ mice/genotype; $t_{(12)}=5.325$, Student's $t$ test). e Rgs $7^{-/-}$mice show a lower stress-induced hyperthermia (SIH) response (T2-T1) compared to $R g s 7^{+/+}$mice $\left(n=14-15 /\right.$ genotype; $t_{(27)}=8.828$, Student's $t$ test). f Rgs $7^{-1-}$ mice buried fewer marbles compared to $R g s 7^{+/+}$littermates in the marble burying test $\left(t_{(18)}=2.185\right.$, Student's $t$ test). g Rgs $7^{-1-}$ mice spent significantly more time in the open arm $\left(t_{(18)}=2.316\right.$, Student's $t$ test) and entered more frequently $\left(t_{(18)}=2.158\right.$, Student's $t$ test) in the open arm during the EPM test. Rgs ${ }^{-1-}$ mice displayed decreased immobility time in the $\mathbf{h}$ TST $\left(t_{(18)}=3.327\right.$, Student's $t$ test) and i FST $\left(t_{(18)}=2.584\right.$, Student's $t$ test). $\mathbf{j}$ Emotionality scores were integrated from four behavioral tests (marble burying, elevated plus maze, tail suspension test, and force swim test) and normalized to $\operatorname{Rgs} 7^{+/+}$mice. A lower emotionality score for $R g s 7^{-1-}$ mice indicates an antidepressant-like phenotype $(n=10$ mice/genotype; $t_{(18)}=7.737$, Student's $t$ test). $\mathbf{k}$ Emotionality score $\left(n=9-11\right.$ mice/group; treatment $F_{(1,36)}=17.32$, genotype $F_{(1,36)}=103.4$, interaction $F_{(1,36)}=21.24$, two-way ANOVA with Bonferroni post hoc test) and I sucrose preference test for Rgs $7^{+/+}$and Rgs $7^{-/-}$mice subjected to unpredictable chronic mild stress (UCMS; $n=9-11$ mice/group; treatment $F_{(1,36)}=33.51$, genotype $F_{(1,36)}=6.018$, interaction $F_{(1}$, ${ }_{36}=6.135$, two-way ANOVA with Bonferroni post hoc test). Data are mean \pm SEM $\left({ }^{*} P<0.05,{ }^{* *} P<0.01,{ }^{* * *} P<0.001,{ }^{* * * *} P<0.0001\right)$ 
mice corresponding to an anxiolytic and antidepressant-like phenotype (Fig. 1j). Female Rgs $7^{-1-}$ mice also displayed a lower emotionality score compared to their wild-type littermates (Supplementary Figure 2a-e) demonstrating the behavioral effect due to the absence of RGS7 is independent of sex.

We further sought to explore the role of RGS7 in stress, by utilizing a chronic stress-induced depression model, the UCMS paradigm. $R g s 7^{+/+}$mice that underwent UCMS showed increased marble burying, had fewer crossovers in the open arm in the EPM test, and exhibited increased immobility in the TST and FST compared to non-stressed (Ctrl) $R g s 7^{+/+}$mice (Supplementary Figure 3a-d). As expected, $R g s 7^{+1+}$ mice exposed to UCMS displayed a higher emotionality score, demonstrating a depressive-like phenotype (Fig. 1k). In contrast, Rgs $^{-/-}$mice subjected to UCMS were resilient to the chronic stress as evident in both the individual behavioral tests as well as from the emotionality score (Fig. $1 \mathrm{k}$ and Supplementary Figure 3a-d). Another key feature of this paradigm is the ability to induce anhedonia-like behavior as measured in a two-bottle sucrose preference test. UCMS reduced the sucrose preference in $R g s 7^{+/+}$ mice but had no effect on $\mathrm{Rgs}^{-1-}$ mice indicating their resilience to stress-induced anhedonia (Fig. 1l). These observations indicate that deletion of RGS7 induces an antidepressant-like behavioral response, which phenocopies what was reported in the GPR158 knockout mice [38].

Membrane targeting of RGS7 by GPR158 is required for the modulation of behavioral effects

To determine the role of the MPFC and developmental adaptations in the antidepressant-like behavior, we took advantage of available conditional $R g s 7^{\text {loxP/loxP }}$ strain combined with a viral delivery of Cre recombinase (Fig. 2a, b). Stereotaxic injections of AAV-Cre virus into the mPFC of adult mice substantially decreased RGS7 expression in the region (Fig. 2c). AAV-Cre mice displayed a significant reduction in immobility time in the TST (Fig. 2d) and FST (Fig. 2e), with only a trend toward fewer number of marbles buried (Fig. 2f) and increased time spent in the open arm of the EPM test (Fig. 2g). Overall, mice with a loss of RGS7 in the mPFC (AAV-cre) showed a reduction in the emotionality score (Fig. 2h) recapitulating the antidepressant-like phenotype observed in the global knockout.

Rescue experiments were also performed by bilaterally injecting AAV expressing RGS7 into the mPFC of Rgs $^{-1-}$ mice (Fig. 3a). This manipulation restored RGS7 expression to wild-type levels as evidenced by immunoblotting (Fig. 3b). We observed that $R g s 7^{-1-}$ mice injected with AAV-RGS7 but not with control virus (AAVVenus) buried more marbles and exhibited increased immobility times in TST and FST (Fig. 3c-f), indicating that restoration of RGS7 expression in mPFC was sufficient for reversing the antidepressant-like phenotype associated with global loss of RGS7.

To probe the relationship between RGS7 and GPR158 more directly, we virally expressed RGS7 in the MPFC of Gpr158 ${ }^{-/-}$mice. This not only rescued RGS7 expression deficits but also increased it above wild-type levels (Fig. 3g). However, unlike in the experiments with $R g s 7^{-1-}$ mice described above, we found that this manipulation had no effect on performance of $\mathrm{Gpr}_{158^{-/-}}$in any of the tests, including marble burying, EPM, TST, and FST (Fig. 3h-k) indicating that RGS7 alone outside of complex with GPR158 is not sufficient for driving stress-induced responses. Comparing the emotionality scores from these experiments further reinforces the conclusion that RGS7 requires GPR158 to have an impact on depression-like behaviors (Fig. 3I).

To gain insight into the mechanism of GPR158's dependency on RGS7 antidepressant-like effect, we first studied the subcellular distribution of RGS7 by biochemical fractionation in different stress-induced depression models, UCMS and PRS. We observed significant recruitment of RGS7 to the membrane fraction in mice exposed to UCMS or PRS and corresponding loss from the cytosol
(Fig. 4a). Stress exposure did not affect the total levels of RGS7. A positive correlation between RGS7 recruitment and immobility in the TST was found for both chronic stress models (Fig. 4b). Furthermore, this effect required GPR158 as no increase in RGS7 recruitment to the plasma membrane by stress was observed in mice lacking GPR158 (Fig. 4c, d). These observations suggest that GPR158 exerts its effects by promoting RGS7 recruitment to the membrane.

To probe whether changes in RGS7 localization on the plasma membrane alone influences depression-related behaviors, we studied the effects of the R7-binding partner (R7BP). R7BP is a membrane-tethered protein that forms a complex with RGS7 and its ablation in mice results in a reduction of RGS7 targeting to the plasma membrane [42-44] (Supplementary Figure 4a). Much like GPR158, we found R7BP to be co-expressed with RGS7 in the majority of $\mathrm{MPFC}$ neurons as revealed by high-resolution in situ hybridization (Supplementary Figure 4b). Furthermore, there was a complete overlap in $R 7 b p$ and Gpr158 signals indicating that both plasma membrane tethering mechanisms operate in the same neurons (Supplementary Figure 4c). Next, we analyzed a possible role of RGS7 tethering by R7BP in modulating depressive-like behaviors. Evaluation of $R 7 b p^{-1-}$ mice in a panel of tests did not reveal appreciable differences in their behaviors as compared to $R 7 b p^{+/+}$littermates, with the exception of an increase in the TST immobility time, and no significant effects on emotionality score were noted (Supplementary Figure 4d-h). These data illustrate a unique role of GPR158-mediated targeting of RGS7 to the plasma membrane in controlling mood-related behaviors and suggest that modulation of stress-induced behavioral responses requires the concerted action of GPR158 and RGS7.

\section{GPR158-RGS7 complex controls homeostatic cAMP production} We next focused on elucidating the molecular mechanisms of GPR158-RGS7 action. Considering that RGS7 is a modulator of heterotrimeric $G_{i / o}$ proteins that directly controls the activity of their effector enzyme, AC, we hypothesized that GPR158-RGS7 complex may exert its behavioral effects through CAMP. Indeed, we found significant increases in the total CAMP levels in the mPFC of $\operatorname{Rgs}^{-1-}$ (Fig. 5a), similar to the effect reported in $\mathrm{Gpr}_{158^{-/-}}$mice [38]. Persistent activation of $\mathrm{G}$ protein signaling due to chronic activation of $\mathrm{G}_{\mathrm{i} / \mathrm{o}}$ coupled GPCRs is well known to lead to a compensatory increase in CAMP production through the sensitization of AC activity. To a large extent this CAMP production is contributed by GBY [45-49], which stimulates many AC isoforms. Since loss of RGS control also results in persistent activation of $G$ protein signaling [30,41, 50-52], we hypothesized that GPR158RGS7 may affect CAMP production by AC sensitization. Indeed, we observed a substantial increase in the basal AC activity in MPFC membranes of Rgs $^{-1-}$ (Fig. 5b) and Gpr $158^{-1-}$ mice (Fig. 5c). This effect was completely abolished by incubating with the $G \beta \gamma$ scavenger peptide derived from GRK2, suggesting that it is mediated by the G $\beta \gamma$. Consistent with this, the membranes prepared from mPFC regions of $\mathrm{Rgs}^{-1-}$ and $\mathrm{Gpr}_{158^{-1-}}$ mice exhibited greater sensitivity to stimulation by recombinant GasGTP, a hallmark of G $\beta \gamma$ action. This facilitation was again blocked by scavenging $G \beta \gamma$ indicating the specificity of the effect (Fig. $5 \mathrm{~d}-\mathrm{g}$ ).

Since the levels of active $G$ proteins in the cells are ultimately shaped by the balance between GPCR-induced activation and RGS-mediated inhibition, we next sought to determine the identity of the GPCRs contributing to elevation of tonic G protein signaling to $A C$ and the resultant effects on behavior upon loss of GPR158-RGS7 complex. We started by performing a pharmacological suppressor screen evaluating the effects of antagonizing $\mathrm{G}_{\mathrm{i} / \mathrm{o}^{-}}$ coupled GPCRs with known roles in mood regulation and/or prominent expression in the $\mathrm{mPFC}$ on reverting the antidepressant-like behaviors in $G p r 158^{-1-}$ mice. We found that blockade of the $a_{2 A}$-adrenergic (ADRA2A) by yohimbine and 
a

AAV-Cre:

AAV-Venus:

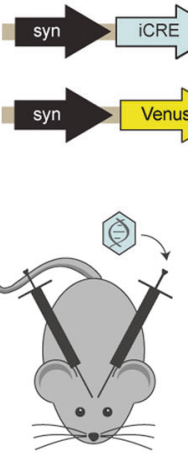

Rgs7loxP/loxp

b
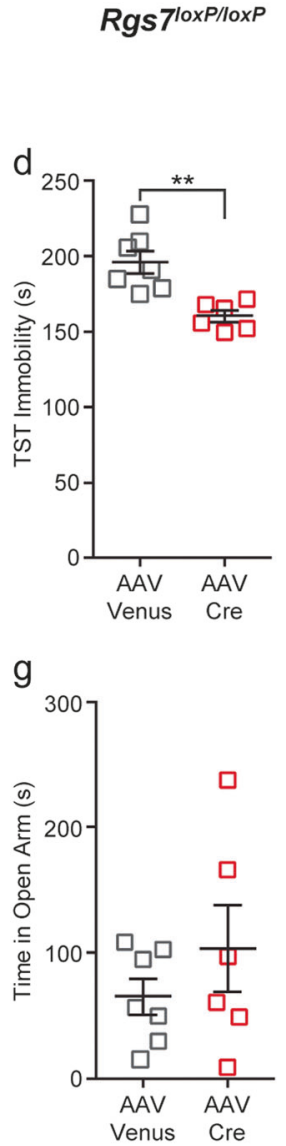

C
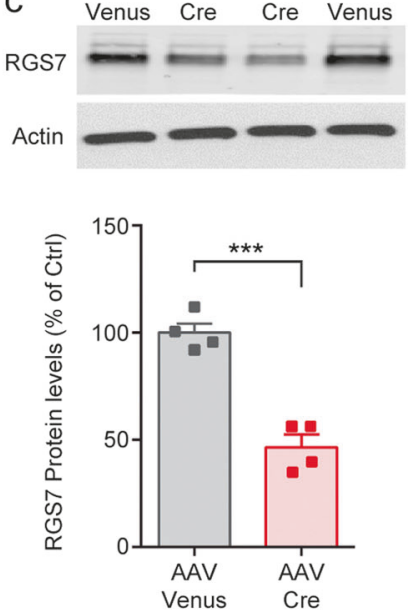

f
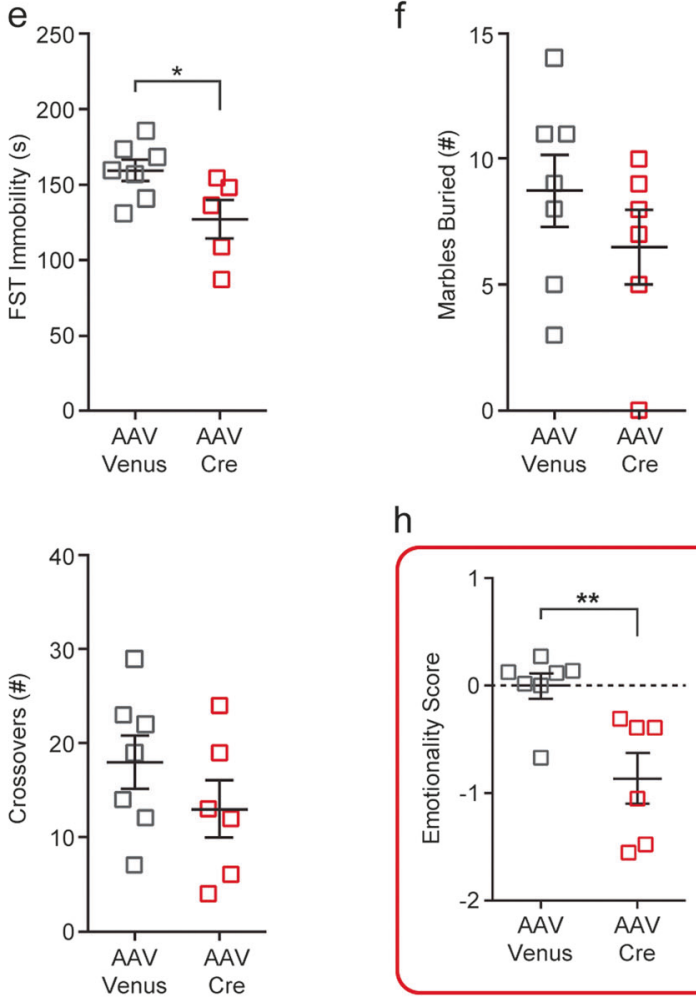

h

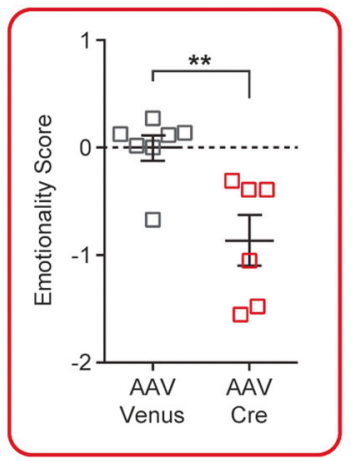

Fig. 2 Elimination of RGS7 in the mPFC induces an antidepressant-like phenotype. a Scheme of AAV-Cre injected bilaterally into the mPFC of Rgs $7^{\text {loxP/loxP }}$ mice. b Representative image of viral expression in the mPFC. c Western blot analysis of RGS7 levels confirmed a decrease after AAV-Cre injection ( $n=4-5 /$ group; $t_{(6)}=7.083$, Student's $t$ test). Performance of the AAV-Cre and AAV-Venus injected mice in the d tail suspension test $\left(t_{(11)}=4.196\right.$, Student's $t$ test), e forced swim test $\left(t_{(11)}=2.449\right.$, Student's $t$ test), $\mathbf{f}$ marble burying test, and $\mathbf{g}$ elevated plus maze. h AAV-Cre injected mice show a lower emotionality score compared with AAV-Venus-injected mice $\left(n=6-7\right.$ mice/group; $t_{(11)}=3.454$, Student's $t$ test). Data are mean \pm SEM $\left({ }^{*} P<0.05,{ }^{* *} P<0.01,{ }^{* * *} P<0.001\right)$

GABAB by CGP35348 completely reversed the antidepressant-like phenotype of $\mathrm{Gpr} 158^{-/-}$mice without affecting the behavior of wild-type littermates in the TST (Supplementary Figure 5a) and FST (Fig. 5h, i). In contrast, blockade of $\mu$-opioid, 5-HT1A, or dopamine D2 receptors by naloxone, WAY100636, and raclopride, respectively did not affect the behavior of mice in the TST task, indicating the selectivity of the effects (Supplementary Figure 5a). Importantly, yohimbine or CGP35348 administration also reduced CAMP levels in the mPFC of Gpr158 $8^{-1-}$ mice without affecting Gpr158 $8^{+/+}$littermates (Fig. 5j). These findings reinforce the model that effects seen upon elimination of GPR158-RGS7 complex likely result from increase in $\mathrm{G}_{\mathrm{i} / \mathrm{o}}$ activation by GPCRs due to the loss of their negative regulation.

Finally, we tested the model in a reconstituted system to determine the sufficiency of the identified players in driving the observed biochemical changes. We monitored real-time changes in CAMP concentration induced by AC sensitization in response to chronic GPCR activation. We observed precipitous surge in CAMP production driven by ADRA2A or GABABR transfected into HEK293 cells (Fig. 5k, I and Supplementary Figure 5b, c). This effect was 
a

AAV-Venus

or AAV-RGS7

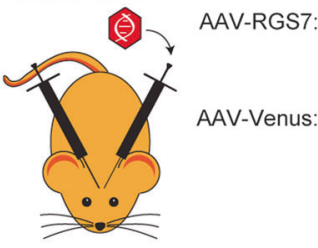

Rgs7 $\%$

C

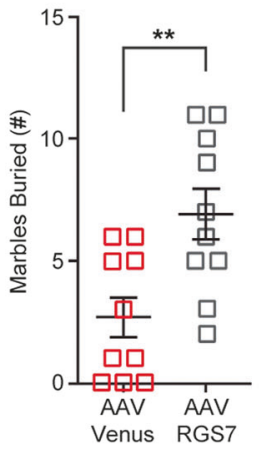

g

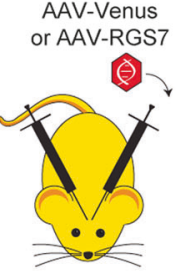

Gpr158 d
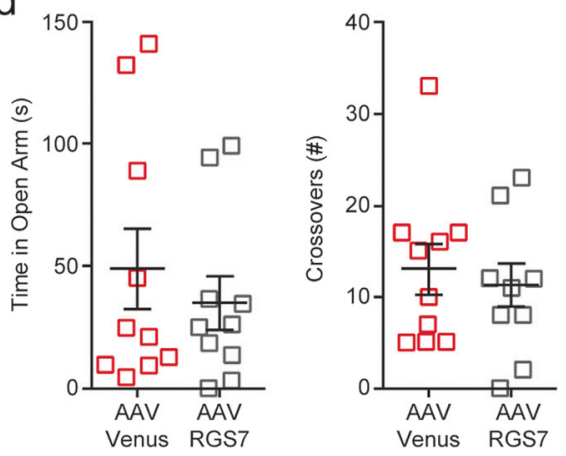

b
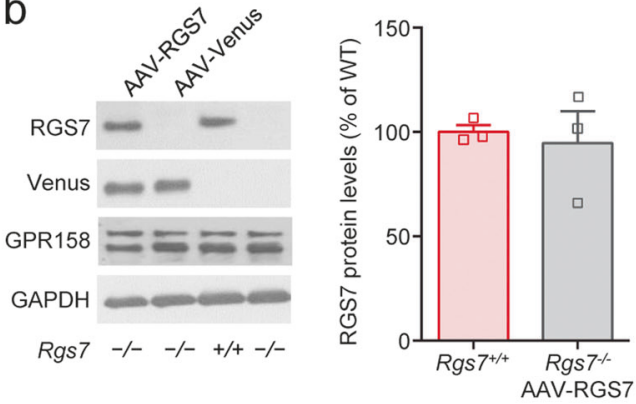

e

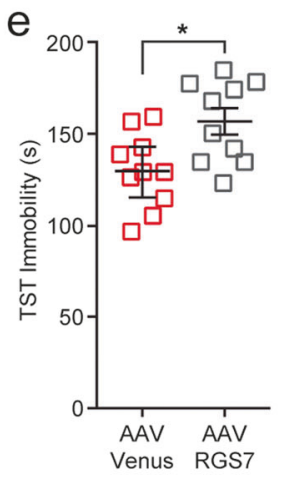



h
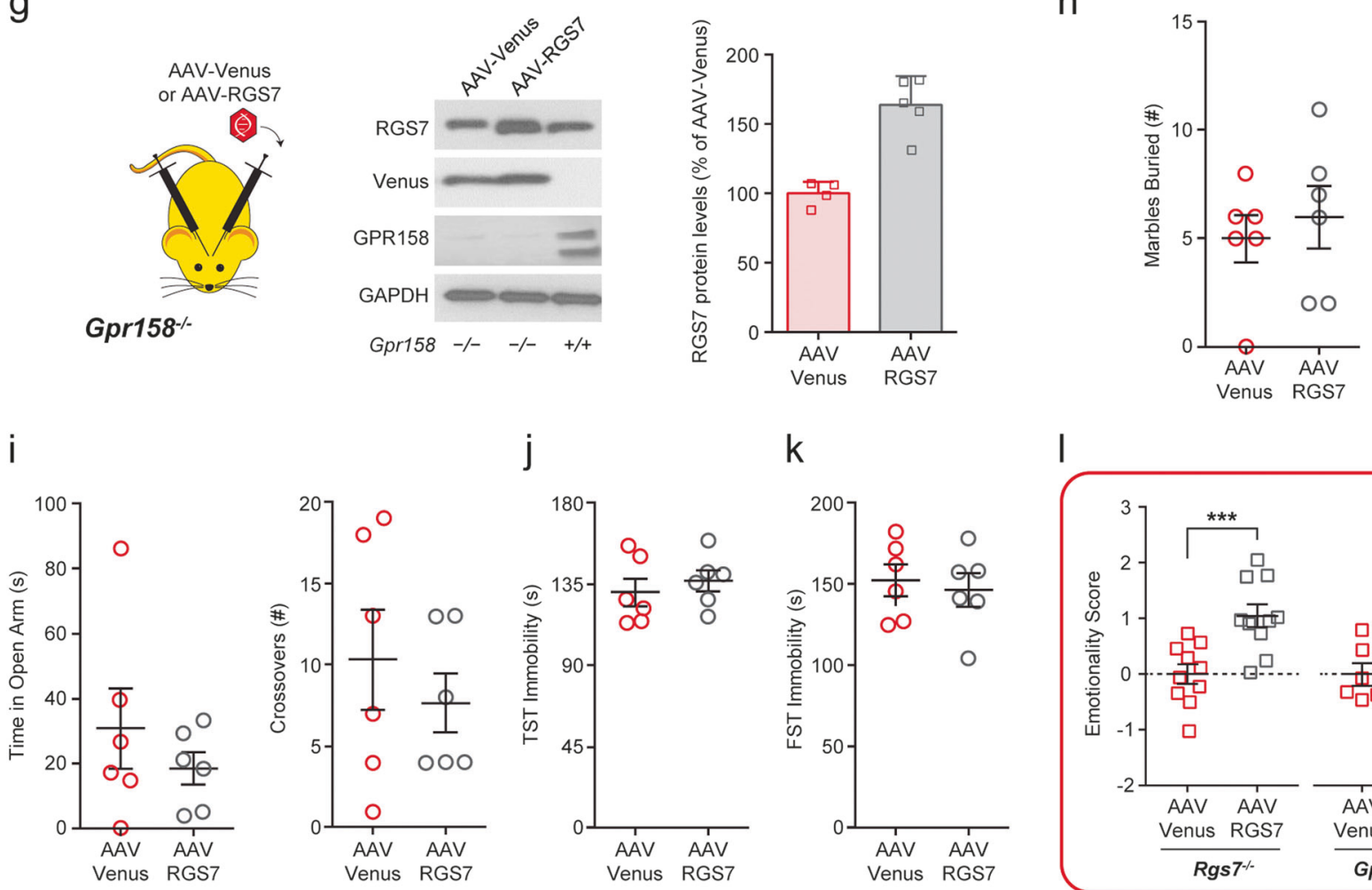

k

I
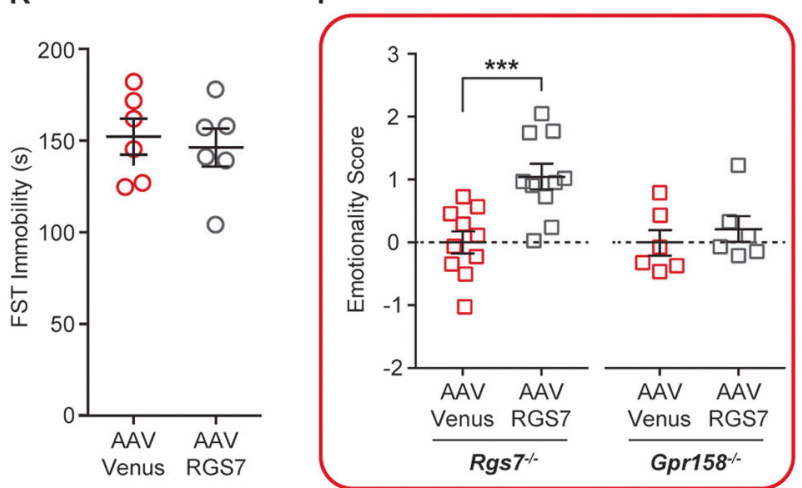

Fig. 3 RGS7 and GPR158 act as a complex in controlling behavioral adaptations. a Scheme of RGS7 expressing AAV and diagram of the experimental protocol. b Western blots and quantification of RGS7 levels in the mPFC of Rgs $7^{-1-}$ mice after viral injection. Rgs7 $7^{-1-}$ mice injected with AAV-RGS7 or AAV-Venus underwent c marble burying test $\left(t_{(18)}=3.200\right.$, Student's $t$ test), $\mathbf{d}$ elevated plus maze, e tail suspension test $\left(t_{(18)}=2.822\right.$, Student's $t$ test), and f forced swim test $\left(t_{(18)}=2.122\right.$, Student's $t$ test; $n=10$ mice/group). $g$ Representative western blots and

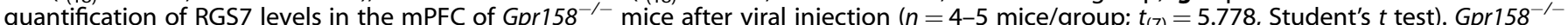
mice injected with AAV-RGS7 or AAV-Venus underwent $\mathbf{h}$ MB, i EPM, j TST, and $\mathbf{k}$ FST. I Rgs7 ${ }^{-1-}$ mice injected with AAV-RGS7 show a significant increase in the emotionality score $\left(n=10\right.$ mice/group; $t_{(18)}=3.892$, Student's $t$ test) while $G p r 158^{-/}$mice injected with AAV-RGS7 are not significantly different to AAV-Venus-injected controls in the emotionality score ( $n=6$ mice/group; Student's $t$ test). Data are mean \pm SEM ( ${ }^{*}<<$ $0.05,{ }^{* *} P<0.01 ;{ }^{* * *} P<0.001$, ns not significant) 
a

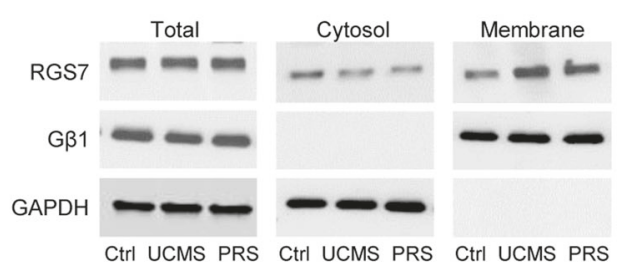



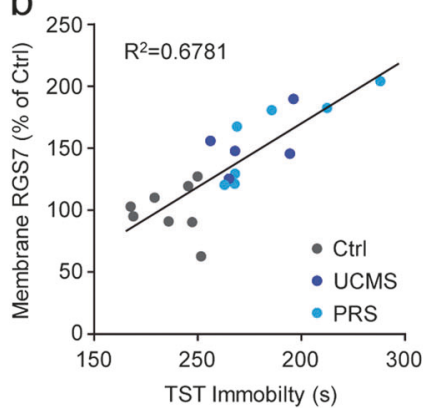

C

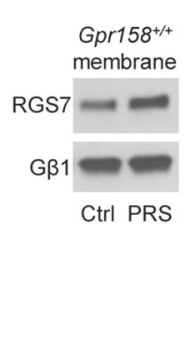

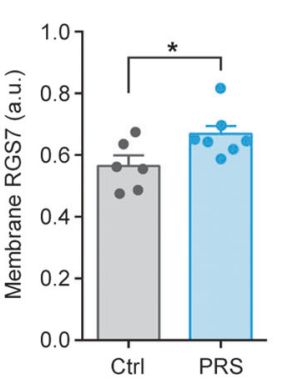

d

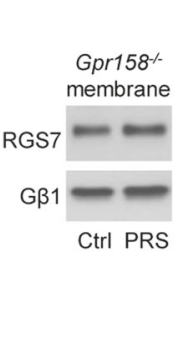

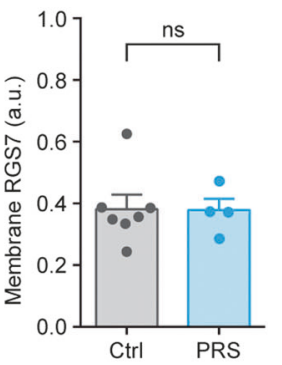

Fig. 4 Increase in membrane-bound RGS7 by chronic stress is dependent on GPR158. a Representative western blots and quantification of RGS7 in the cytosol, membrane fraction, and in the total lysate of mPFC of mice subjected to unpredictable chronic mild stress (UCMS) or physical resistant stress (PRS). GAPDH and G $\beta 1$ were used as cytosol and membrane marker, respectively $\left(n=5-9\right.$ mice/group; cytosol $F_{(2,17)}=$ 1.597 , membrane $F_{(2,17)}=1.558$, one-way ANOVA with Bonferroni post hoc vs crtl in each fraction). $\mathbf{b}$ Correlation between RGS7 levels at the plasma membrane in MPFC and immobility time in the tail suspension test from control and stressed-mice (Pearson $R^{2}=0.6781$ ). Representative western blots and quantification of membrane RGS7 in the mPFC of c Gpr158 ${ }^{+/+}\left(t_{(11)}=2.35\right)$ and $\mathbf{d}$ Gpr158 $8^{-/-}$mice subjected to PRS ( $n=4-6$ mice/group; Student's $t$ test)

partially mediated by GßY. Importantly, RGS7 was able to potently suppress the $G \beta \gamma$-dependent component of the $A C$ sensitization driven by chronic activation of both ADRA2A and GABAB receptors followed by the acute blockade of the receptors (Fig. $5 \mathrm{k}$, I and Supplementary Figure 5b, c). Thus, our observations in the reconstituted system support a model involving GPR158-RGS7 complex in controlling the availability of activated $\mathrm{G}$ proteins to affect homeostatic scaling of cAMP production.

\section{DISCUSSION}

It is well accepted that exposure to stress substantially contributes to the pathogenesis of affective disorders, including MDD and anxiety. A better understanding of the cellular and molecular elements that underlie an individual's vulnerability to stressrelated disorders will likely accelerate the development of pharmacotherapy for their amelioration. With this overall goal in mind, the present work focused on a newly identified player in the process. We have recently found that the orphan receptor GPR158, plays a key role in the development of stress-induced depression [38]. Yet, the mechanisms whereby it exerted its effects remained unclear. Our findings reported in this manuscript point to an unconventional model, not previously reported for GPCR-like receptors. We found that instead of serving in a capacity of a canonical signaling GPCR, which activates heterotrimeric G proteins, GPR158 effects on mood-related behaviors are mediated by recruiting a negative regulator of heterotrimeric $G$ proteins, RGS7. This conclusion is based on multiple lines of evidence. We show that lack of RGS7 in a mouse model phenocopied the antidepressant-like behaviors observed in Gpr $158^{-/-}$mice, as well as its resilience to chronic stress-induced depression. Furthermore, viral manipulations revealed an essential role of RGS7-GPR158 complex in rescuing the antidepressant-like phenotype in the knockout models. Further studies would be needed to identify the neuronal subpopulation in the MPFC responsible for the observed behavioral effects; however, we previously showed that chronic stress increases GPR158 expression specifically in glutamatergic neurons with no effect on GABAergic neurons [38]. At the molecular level, we show that GPR158 exerts its control on RGS7 directing it to the plasma membrane, placing it in close proximity to the heterotrimeric $G$ proteins that are substrates of RGS7 catalytic action. Indeed, increased levels of GPR158 in chronically stressed mice, result in the translocation of RGS7 to the membrane, decreasing its cytosolic fraction, whereas this change in subcellular localization is absent in chronically stressed Gpr158 $8^{-1-}$ mice. Furthermore, it appears that GPR158-RGS7 likely acts in a capacity of a GTPase accelerating protein (GAP) complex to mediate its effects on depression-related behavior, defying conventional mode of GPCR effects usually acting as guanine nucleotide exchange factors (GEFs) (Supplementary Figure 6). In this model, RGS7 associates with GPR158 utilizing distinct docking sites on the receptor that require contributions of both the DEP domain of RGS7 and associated G 35 subunit [28]. However, despite the requirement for the $G \beta$ subunit for binding such anchoring of RGS complex to GPR158 does not require Ga subunit and thus is mechanistically distinct from canonical interactions of GPCRs with their Ga substrates.

One of the major findings of this work links this RGS system to the homeostatic regulation of CAMP, thereby impacting the effects of stress and depression-like behaviors. By modulating $\mathrm{G}_{\mathrm{i} / \mathrm{o}}$ signaling, this GAP complex comprised of GPR158 and RGS7 regulates the activity of membrane $A C$, the enzyme responsible for cAMP production. Interestingly, changes in intracellular CAMP in the brain have been implicated in mood regulation. Decreased cAMP levels and resultant effects on downstream signaling cascades are consistently associated with the development of depressive symptoms [24, 25]. Furthermore, the efficacy of antidepressant pharmacotherapy is heavily dependent on the 

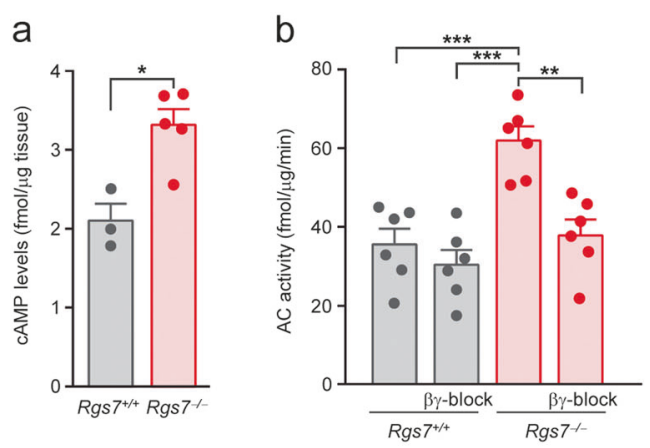

d

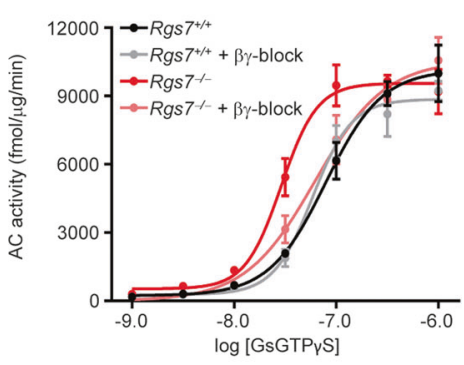

f

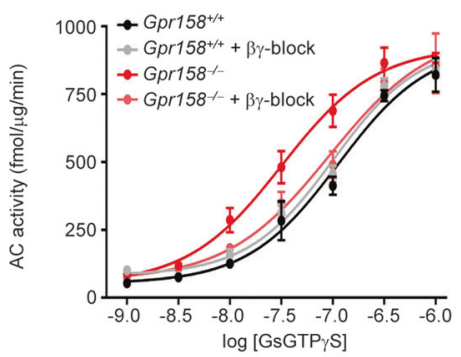

$\mathrm{h}$

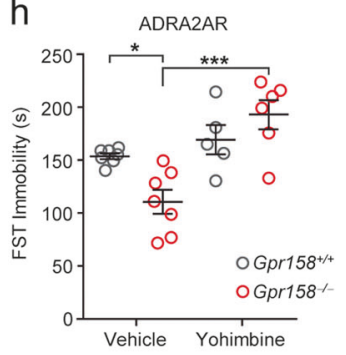

i

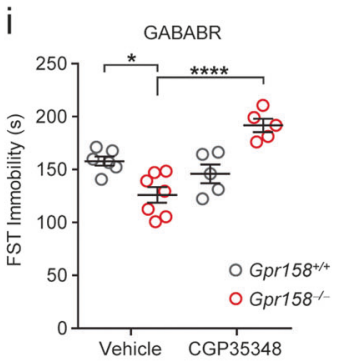

k
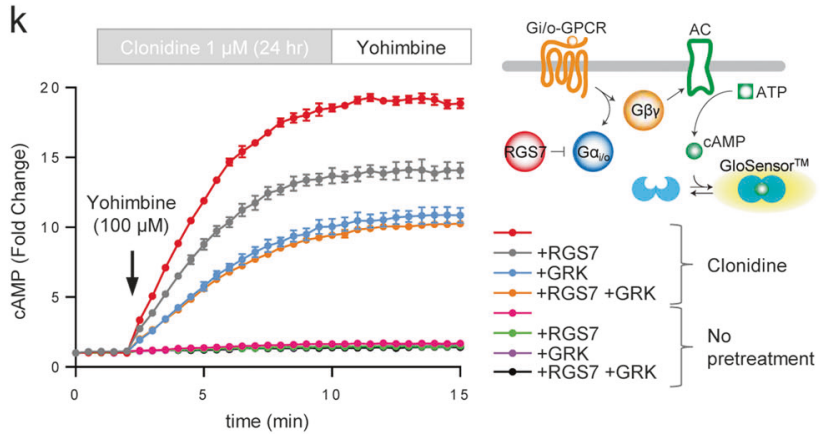

C

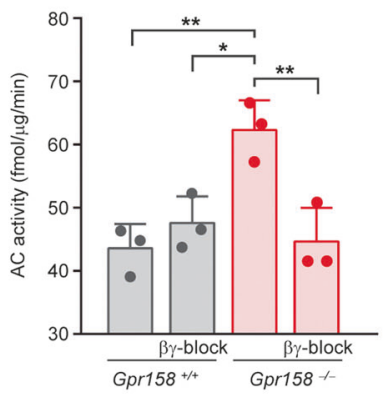

e
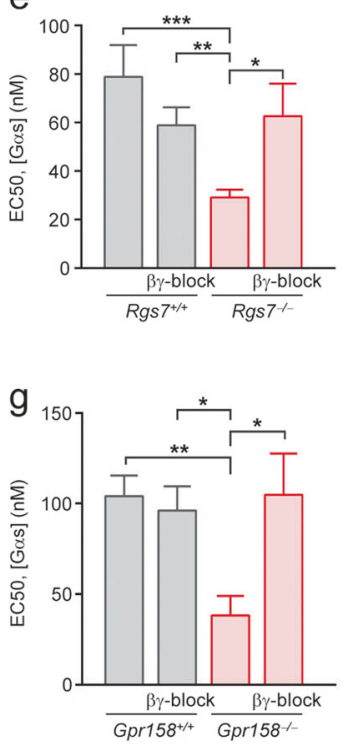

j

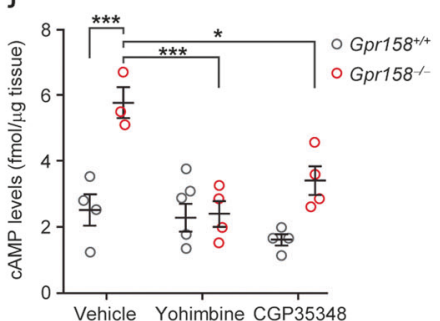

|

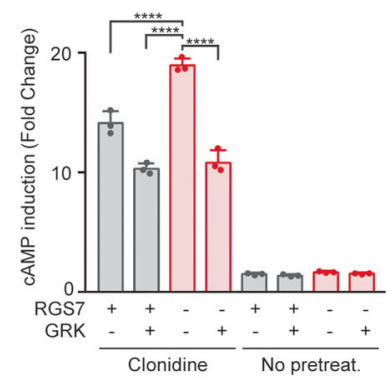

restoration of a normal cAMP homeostasis [24, 53, 54]. Several members of the RGS protein family actively control CAMP production by regulating the extent of inhibitory $G_{i / o}$ signaling between GPCRs and ACs $[41,51,55]$. Our model suggests that the GPR158-RGS7 complex acts as a potent negative modulator of $\mathrm{G}_{\mathrm{i} / \mathrm{o}}$ signaling by targeting the GTPase-accelerating catalytic activity of RGS7 toward defined GPCRs. Disruption of this complex potentiates several $G_{i / o}$-coupled receptors signaling cascades in the mPFC. The resultant chronic over-activation of $G$ proteins is accompanied by release of free $G \beta \gamma$ subunits, which leads to the 
Fig. 5 GPR158-RGS7 complex controls sensitization of adenylate cyclase upon activation of $\mathrm{G}_{\mathrm{i} / \mathrm{o}}$-coupled receptors. a Basal levels of cAMP in the $\mathrm{mPFC}$ of $R g s 7^{+/+}$and $R g s 7^{-1-}$ mice $\left(n=3-5\right.$ mice/genotype; $t_{(6)}=3.794$, Student's $t$ test). b Measurements of basal adenylate cyclase (AC) activity in mPFC membrane preparation of $R g s 7^{+/+}$and $R g s 7^{-1-}$ mice with or without GRK2i ( $\beta \gamma$-block) incubation ( $n=6$ mice/genotype; genotype $F_{(1,20)}=19.61$, treatment $F_{(1,20)}=14.62$, interaction $F_{(1,20)}=6.032$, two-way ANOVA with Bonferroni post hoc test). c Basal AC activity in mPFC membrane preparation of $\mathrm{Gpr}_{158^{+/+}}$and $\mathrm{Gpr} 158^{-1 /-}$ mice with or without GRK2i incubation ( $n=3$ mice/genotype; genotype $F_{(1,8)}=9.094$, treatment $F_{(1,8)}=6.628$, interaction $F_{(1,8)}=16.84$, two-way ANOVA with Bonferroni post hoc test). d Dose-response curve of AC activity after stimulation with Gs-GTP $\gamma \mathrm{S}$ in $\mathrm{Rgs} 7^{+/+}$and $\mathrm{Rgs7^{-1- }} \mathrm{mPFC}$ membranes with or without GRK2i incubation ( $n=5$ mice/genotype). e $\mathrm{EC}_{50}$ comparison between $\mathrm{Rgs7^{+/+ }}$ and $\mathrm{Rgs7^{-1- }}$ mice with or without GRK2i incubation $\left(F_{(3,68)}=4.003\right.$, one-way ANOVA with Tukey's post hoc test). f Dose-response curve of AC activity after stimulation with Gs-GTP $\gamma S$ in Gpr158 ${ }^{+/+}$and $G p r 158^{-1-}$ mPFC membranes with or without GRK2i incubation ( $n=3$ mice/genotype). g EC 50 comparison between $G p r 158^{+/+}$and $G p r 158^{-1-}$ mice with or without GRK2i incubation $\left(F_{(3,68)}\right.$ $=4.310$, one-way ANOVA with Tukey's post hoc test). Immobility time in the FST for Gpr $158^{+/+}$and Gpr158 ${ }^{-/-}$mice treated with $\mathbf{h}$ yohimbine $\left(n=5-7\right.$ mice/group; treatment $F_{(1,21)}=20.38$, interaction $F_{(1,21)}=9.370$, two-way ANOVA with Bonferroni post hoc test) or i CGP35348 ( $n=5-7$ mice/group; treatment $F_{(1,19)}=14.75$, interaction $F_{(1,21)}=30.36$, two-way ANOVA with Bonferroni post hoc test). $\mathbf{j}$ cAMP levels in mPFC of $G_{p r 158^{+/+}}$and Gpr158 $8^{-/-}$mice injected with saline, yohimbine, or CGP35348 ( $n=3-5$ mice/group; genotype $F_{(1,17)}=26.56$, treatment $F_{(2,17)}$ $=11.30$, interaction $F_{(2,17)}=7.241$, two-way ANOVA with Bonferroni post hoc test). $\mathbf{k}$ Cell-based assay to measure the kinetic of cAMP level modulation. ADRA2A antagonist yohimbine was added to cells expressing ADRA2A receptor and pretreated with clonidine at the indicated time point. The normalized change in luminescence, which reflects the change in CAMP concentration, was continuously recorded in live cells. RGS7 expression reduced the amount of cAMP and the G $\beta \gamma$-scavenger GRK abolished the superactivation of adenylate cyclase $\left(n=3 ; F_{(7,16)}=\right.$ 293.9, one-way ANOVA with Tukey's post hoc test). I cAMP induction $15 \mathrm{~min}$ after yohimbine application for each condition. Data are mean \pm SEM $\left({ }^{*} P<0.05,{ }^{*} P<0.01,{ }^{* * *} P<0.001,{ }^{* * * *} P<0.0001\right)$

sensitization of many AC subtypes [46-49]. Several studies have previously suggested a role for RGS proteins in heterologous sensitization of ACs. For example, the complex RGS9-2/G 35 inhibits the $\mu$-opioid receptor-mediated sensitization of $A C 5$ in both the mouse striatum and in a reconstituted system in HEK293 cells [41]. Similarly, expression of RGS-insensitive $\mathrm{Ga}_{o}$ has been shown to enhance potency and efficacy of by $\mu$-opioid receptormediated sensitization in C6 glioma cells [56]. Recently available knock-in mouse model expressing RGS-insensitive $\mathrm{Ga}_{\mathrm{i} 2}$ subunits represents a powerful tool to link this molecular mechanism and its behavioral consequences $[57,58]$. Importantly, RGS-insensitive $\mathrm{Ga}_{\mathrm{i} 2}$ knock-in mice, which mimic the loss of RGS control, show an antidepressant-like phenotype and decreased anxiety-related behaviors. Concomitantly, these mice exhibit changes in downstream signaling cascades that are suggestive of modulation in cAMP levels, observed in Gpr158 ${ }^{-1-}$ mice [38]. Interestingly, global knockout of a RGS6, a close homolog of RGS7, has also been reported to result in anxiolytic and antidepressant-like phenotypes in mice [59]. RGS6 appears to act as a conventional suppressor of $\mathrm{G}_{\mathrm{i} / \mathrm{o}}$-coupled 5-HT1A receptor leading to disinhibition of CAMP production upon its elimination making the mechanism that we describe for the RGS7 action distinct and thus non-redundant with RGS6. Overall, these observations support our model that the mood-modifying action of the GPR158-RGS7 complex is mediated by $G \beta Y$ modulation of $A C$ activity and subsequent change in the CAMP production.

In addition, to its GAP effects on $\mathrm{Ga}_{\mathrm{i} / \mathrm{o}}$ proteins, GPR158 could also exert effects on cellular signaling and mood regulation via a GEF-mediated activation of $\mathrm{Ga}_{\mathrm{q}}$. This mechanism was reported to occur in CA1 pyramidal neurons in hippocampus in response to its activation by bone-derived hormone osteocalcin [29]. The relationship between these two mechanisms, as well as their relative contributions to mood regulation and stress responses are unclear at the moment. However, the inability to rescue depression-related behaviors by RGS7 overexpression in the absence of GPR158 suggests that at least in the MPFC neurons, GPR158 effects on mood require its GAP activity via the complex formation with RGS7. Further studies are needed to extend our understanding on regional specificity of GPR158 signaling properties and their contributions to behavior.

Our study further uncovered the role of GPR158-RGS7 complex in controlling mood regulation by modulating signaling of traditional GPCRs. Pharmacological rescue experiments revealed that the loss of GPR158 exerts its antidepressant-like effects via the augmentation of GABAB and ADRA2A receptor signaling. Mechanistic studies in the reconstituted system confirmed that these effects are mediated by the ability of GPR158-RGS7 to negatively regulate $\mathrm{Ga}_{\mathrm{i} / \mathrm{o}}$ signaling that is initiated by these traditional GPCRs. Thus, the GPR158-RGS7 complex serves as a downstream integrator of $G$ protein signaling for traditional GPCRs by controlling the strength of $\mathrm{G}$ protein flux to signaling cascades involved in mediating antidepressant effects. However, we also observed some selectivity for which $\mathrm{GPCR}-\mathrm{Ga}_{\mathrm{i} / \mathrm{o}}$ signaling this complex is able to regulate. For example, we could not detect any pharmacological rescue upon blockade of $\mu$-opioid, D2, or 5-HT1A receptors. These results could be explained by insufficient contribution of these receptors to $G$ protein activation in the mPFC neurons. Alternatively, and perhaps more provocatively, it suggests that GPR158 may direct RGS7 action toward specific GPCRs at the molecular level. Studies on the homologous orphan receptor GPR179, which similarly associates with RGS7 but is only expressed in the retina, support this possibility. In the retina neurons, GPR179-RGS7 complex regulates signaling properties of the metabotropic glutamate receptor mGluR6 [30, 60-63], which require the macromolecular assembly of several components, including the direct association between GPR179 and mGluR6 [64]. Thus, it is tempting to speculate that GPR158 in mPFC neurons can likewise direct RGS7 to regulate a subset of GPCRs via physical association with such receptors. Uncovering components of this macromolecular complex as well as identifying elements specifically expressed in different neuronal populations across the brain will certainly reveal novel molecular mechanisms of GPCR signaling regulation and decipher their specific biological purpose.

In conclusion, we hope that our findings provide a novel avenue for exploring pharmacotherapeutic options. Currently available pharmacological treatments of major depression are considerably limited by delay in onset of action, severe side effects, and lack of efficacy in drug-resistant population. Given the urgent need of identifying novel druggable targets to alleviate depressive symptoms rapidly and efficiently, the unique complex GPR158RGS7 represents an exciting new candidate.

\section{ACKNOWLEDGEMENTS}

We wish to thank Ms. Natalia Martemyanova for producing and maintaining mice examined in this study and Dr. Samuel Young, Jr. for guidance with viral transfer experiments.

\section{FUNDING AND DISCLOSURE}

The authors declare no competing interests. This work was supported by NIH grants, MH105482 (KAM), DA026405 (KAM), DA041207 (BSM), and by the Canadian Institutes of Health Research Fellowship (LPS). 


\section{AUTHOR CONTRIBUTIONS}

LPS performed behavioral experiments and viral injections. CO, BSM, and CS performed biochemical and cell biological experiments. CO, LPS, and KAM designed the study, analyzed data, and wrote the paper.

\section{ADDITIONAL INFORMATION}

Supplementary Information accompanies this paper at (https://doi.org/10.1038/ s41386-018-0238-y).

Publisher's note: Springer Nature remains neutral with regard to jurisdictional claims in published maps and institutional affiliations.

\section{REFERENCES}

1. Drevets WC, Price JL, Simpson JR Jr, Todd RD, Reich T, Vannier M, et al. Subgenual prefrontal cortex abnormalities in mood disorders. Nature. 1997;386:824-7.

2. Rajkowska G, Miguel-Hidalgo J, Wei J, Dilley G, Pittman SD, Meltzer HY, et al. Morphometric evidence for neuronal and glial prefrontal cell pathology in major depression. Biol Psychiatry. 1999;45:1085-98.

3. Covington HE 3rd, Lobo MK, Maze I, Vialou V, Hyman JM, Zaman S, et al. Antidepressant effect of optogenetic stimulation of the medial prefrontal cortex. J Neurosci. 2010;30:16082-90.

4. Shrestha $P$, Mousa A, Heintz N. Layer $2 / 3$ pyramidal cells in the medial prefrontal cortex moderate stress induced depressive behaviors. Elife. 2015;4. e08752

5. Zhou W, Wang N, Yang C, Li XM, Zhou ZQ, Yang JJ. Ketamine-induced antidepressant effects are associated with AMPA receptors-mediated upregulation of mTOR and BDNF in rat hippocampus and prefrontal cortex. Eur Psychiatry. 2014:29:419-23.

6. Amat J, Baratta MV, Paul E, Bland ST, Watkins LR, Maier SF. Medial prefrontal cortex determines how stressor controllability affects behavior and dorsal raphe nucleus. Nat Neurosci. 2005;8:365-71.

7. Arnsten AF. Stress signalling pathways that impair prefrontal cortex structure and function. Nat Rev Neurosci. 2009;10:410-22.

8. Radley JJ, Rocher AB, Miller M, Janssen WG, Liston C, Hof PR, et al. Repeated stress induces dendritic spine loss in the rat medial prefrontal cortex. Cereb Cortex. 2006;16:313-20.

9. Radley JJ, Rocher AB, Rodriguez A, Ehlenberger DB, Dammann M, McEwen BS, et al. Repeated stress alters dendritic spine morphology in the rat medial prefrontal cortex. J Comp Neurol. 2008;507:1141-50.

10. Yuen EY, Wei J, Liu W, Zhong P, Li X, Yan Z. Repeated stress causes cognitive impairment by suppressing glutamate receptor expression and function in prefrontal cortex. Neuron. 2012;73:962-77.

11. Lucassen PJ, Pruessner J, Sousa N, Almeida OF, Van Dam AM, Rajkowska G, et al. Neuropathology of stress. Acta Neuropathol. 2014;127:109-35.

12. McEwen BS. Glucocorticoids, depression, and mood disorders: structural remodeling in the brain. Metabolism. 2005;54(5 Suppl 1):20-3.

13. Popoli M, Yan Z, McEwen BS, Sanacora G. The stressed synapse: the impact of stress and glucocorticoids on glutamate transmission. Nat Rev Neurosci. 2011;13:22-37.

14. Donati RJ, Rasenick MM. G protein signaling and the molecular basis of antidepressant action. Life Sci. 2003;73:1-17.

15. Hamon $M$, Blier $P$. Monoamine neurocircuitry in depression and strategies for new treatments. Prog Neuropsychopharmacol Biol Psychiatry. 2013;45:54-63.

16. Szafran K, Faron-Gorecka A, Kolasa M, Kusmider M, Solich J, Zurawek D, et al. Potential role of $\mathrm{G}$ protein-coupled receptor (GPCR) heterodimerization in neuropsychiatric disorders: a focus on depression. Pharmacol Rep. 2013;65:1498-505.

17. Willner $P$, Scheel-Kruger J, Belzung $C$. The neurobiology of depression and antidepressant action. Neurosci Biobehav Rev. 2013;37(10 Pt 1):2331-71.

18. Celada P, Puig M, Amargos-Bosch M, Adell A, Artigas F. The therapeutic role of 5HT1 A and 5-HT2A receptors in depression. J Psychiatry Neurosci. 2004;29:252-65.

19. Posternak MA, Zimmerman M. Is there a delay in the antidepressant effect? A meta-analysis. J Clin Psychiatry. 2005;66:148-58.

20. Reid IC, Stewart CA. How antidepressants work: new perspectives on the pathophysiology of depressive disorder. Br J Psychiatry. 2001;178:299-303.

21. Sunahara RK, Dessauer CW, Gilman AG. Complexity and diversity of mammalian adenylyl cyclases. Annu Rev Pharmacol Toxicol. 1996;36:461-80.

22. Plattner F, Hayashi K, Hernandez A, Benavides DR, Tassin TC, Tan C, et al. The role of ventral striatal CAMP signaling in stress-induced behaviors. Nat Neurosci. 2015;18:1094-100.

23. Wang ZZ, Yang WX, Zhang Y, Zhao N, Zhang YZ, Liu YQ, et al. Phosphodiesterase4D knock-down in the prefrontal cortex alleviates chronic unpredictable stressinduced depressive-like behaviors and memory deficits in mice. Sci Rep. 2015;5:11332.
24. Fujita M, Richards EM, Niciu MJ, lonescu DF, Zoghbi SS, Hong J, et al. cAMP signaling in brain is decreased in unmedicated depressed patients and increased by treatment with a selective serotonin reuptake inhibitor. Mol Psychiatry. 2017;22:754-9.

25. Reiach JS, Li PP, Warsh JJ, Kish SJ, Young LT. Reduced adenylyl cyclase immunolabeling and activity in postmortem temporal cortex of depressed suicide victims. J Affect Disord. 1999;56:141-51.

26. Tomita H, Ziegler ME, Kim HB, Evans SJ, Choudary PV, Li JZ, et al. G protein-linked signaling pathways in bipolar and major depressive disorders. Front Genet. 2013;4:297.

27. Orlandi C, Posokhova E, Masuho I, Ray TA, Hasan N, Gregg RG, et al. GPR158/179 regulate $\mathrm{G}$ protein signaling by controlling localization and activity of the RGS7 complexes. J Cell Biol. 2012;197:711-9.

28. Orlandi C, Xie K, Masuho I, Fajardo-Serrano A, Lujan R, Martemyanov KA. Orphan receptor GPR158 is an allosteric modulator of RGS7 catalytic activity with an essential role in dictating its expression and localization in the brain. J Biol Chem. 2015;290:13622-39.

29. Khrimian L, Obri A, Ramos-Brossier M, Rousseaud A, Moriceau S, Nicot AS, et al. Gpr158 mediates osteocalcin's regulation of cognition. J Exp Med. 2017:214:2859-73.

30. Cao Y, Pahlberg J, Sarria I, Kamasawa N, Sampath AP, Martemyanov KA. Regulators of G protein signaling RGS7 and RGS11 determine the onset of the light response in ON bipolar neurons. Proc Natl Acad Sci USA. 2012;109:7905-10.

31. Sutton LP, Ostrovskaya O, Dao M, Xie K, Orlandi C, Smith R, et al. Regulator of Gprotein signaling 7 regulates reward behavior by controlling opioid signaling in the striatum. Biol Psychiatry. 2016;80:235-45.

32. Dalvi A, Rodgers RJ. GABAergic influences on plus-maze behaviour in mice. Psychopharmacology (Berl). 1996;128:380-97.

33. Martinez DM, Barcellos A, Casaril AM, Savegnago L, Lernardao EJ. Antidepressantlike activity of dehydrozingerone: involvement of the serotonergic and noradrenergic systems. Pharmacol Biochem Behav. 2014;127:111-7.

34. Palucha-Poniewiera A, Branski P, Wieronska JM, Stachowicz K, Slawinska A, Pilc A. The antidepressant-like action of mGlu5 receptor antagonist, MTEP, in the tail suspension test in mice is serotonin dependent. Psychopharmacology (Berl). 2014:231:97-107.

35. Reneric JP, Bouvard M, Stinus L. Idazoxan and 8-OH-DPAT modify the behavioral effects induced by either NA, or 5-HT, or dual NA/5-HT reuptake inhibition in the rat forced swimming test. Neuropsychopharmacology. 2001;24:379-90.

36. Workman ER, Niere F, Raab-Graham KF. mTORC1-dependent protein synthesis underlying rapid antidepressant effect requires GABABR signaling. Neuropharmacology. 2013;73:192-203.

37. Colla AR, Oliveira A, Pazini FL, Rosa JM, Manosso LM, Cunha MP, et al. Serotonergic and noradrenergic systems are implicated in the antidepressant-like effect of ursolic acid in mice. Pharmacol Biochem Behav. 2014;124:108-16.

38. Sutton LP, Orlandi C, Song C, Oh WC, Muntean BS, Xie K, et al. Orphan receptor GPR158 controls stress-induced depression. Elife. 2018;7. e33273

39. Guilloux JP, Seney M, Edgar N, Sibille E. Integrated behavioral z-scoring increases the sensitivity and reliability of behavioral phenotyping in mice: relevance to emotionality and sex. J Neurosci Methods. 2011;197:21-31.

40. Skiba NP, Martemyanov KA, Elfenbein A, Hopp JA, Bohm A, Simonds WF, et al. RGS9-G beta 5 substrate selectivity in photoreceptors. Opposing effects of constituent domains yield high affinity of RGS interaction with the G protein-effector complex. J Biol Chem. 2001;276:37365-72.

41. Xie K, Masuho I, Brand C, Dessauer CW, Martemyanov KA. The complex of G protein regulator RGS9-2 and Gbeta(5) controls sensitization and signaling kinetics of type 5 adenylyl cyclase in the striatum. Sci Signal. 2012;5:ra63.

42. Drenan RM, Doupnik CA, Boyle MP, Muglia LU, Huettner JE, Linder ME, et al. Palmitoylation regulates plasma membrane-nuclear shuttling of R7BP, a novel membrane anchor for the RGS7 family. J Cell Biol. 2005;169:623-33.

43. Martemyanov KA, Yoo PJ, Skiba NP, Arshavsky VY. R7BP, a novel neuronal protein interacting with RGS proteins of the R7 family. J Biol Chem. 2005;280:5133-6.

44. Panicker LM, Zhang JH, Posokhova E, Gastinger MJ, Martemyanov KA, Simonds WF. Nuclear localization of the $G$ protein beta 5/R7-regulator of $G$ protein signaling protein complex is dependent on R7 binding protein. J Neurochem. 2010;113:1101-12.

45. Watts VJ, Neve KA. Sensitization of adenylate cyclase by Galpha i/o-coupled receptors. Pharmacol Ther. 2005;106:405-21.

46. Cumbay MG, Watts VJ. Heterologous sensitization of recombinant adenylate cyclases by activation of $\mathrm{D}(2)$ dopamine receptors. J Pharmacol Exp Ther. 2001;297:1201-9.

47. Baker LP, Nielsen MD, Impey S, Hacker BM, Poser SW, Chan MY, et al. Regulation and immunohistochemical localization of betagamma-stimulated adenylyl cyclases in mouse hippocampus. J Neurosci. 1999;19:180-92. 
48. Brust TF, Conley JM, Watts VJ. Galpha(i/o)-coupled receptor-mediated sensitization of adenylyl cyclase: 40 years later. Eur J Pharmacol. 2015;763(Pt B):223-32.

49. Taussig R, Quarmby LM, Gilman AG. Regulation of purified type I and type II adenylylcyclases by $\mathrm{G}$ protein beta gamma subunits. J Biol Chem. 1993;268:9-12

50. Garzon J, Rodriguez-Munoz M, Lopez-Fando A, Garcia-Espana A, SanchezBlazquez P. RGSZ1 and GAIP regulate mu- but not delta-opioid receptors in mouse CNS: role in tachyphylaxis and acute tolerance. Neuropsychopharmacology. 2004;29:1091-104.

51. Hollinger S, Hepler JR. Cellular regulation of RGS proteins: modulators and integrators of $G$ protein signaling. Pharmacol Rev. 2002;54:527-59.

52. Rahman Z, Schwarz J, Gold SJ, Zachariou V, Wein MN, Choi KH, et al. RGS9 modulates dopamine signaling in the basal ganglia. Neuron. 2003;38:941-52.

53. Garcia AM, Martinez A, Gil C. Enhancing cAMP levels as strategy for the treatment of neuropsychiatric disorders. Curr Top Med Chem. 2016;16:3527-35.

54. Wray NH, Schappi JM, Singh H, Senese NB, Rasenick MM. NMDAR-independent, cAMP-dependent antidepressant actions of ketamine. Mol Psychiatry. 2018. https://www.nature.com/articles/s41380-018-0083-8

55. Gerber KJ, Squires KE, Hepler JR. Roles for regulator of $\mathrm{G}$ protein signaling proteins in synaptic signaling and plasticity. Mol Pharmacol. 2016;89:273-86.

56. Clark MJ, Neubig RR, Traynor JR. Endogenous regulator of G protein signaling proteins suppress Galphao-dependent, mu-opioid agonist-mediated adenylyl cyclase supersensitization. J Pharmacol Exp Ther. 2004;310:215-22.

57. Neubig RR. RGS-insensitive G proteins as in vivo probes of RGS function. Progress Mol Biol Transl Sci. 2015;133:13-30.
58. Talbot JN, Jutkiewicz EM, Graves SM, Clemans CF, Nicol MR, Mortensen RM, et al. RGS inhibition at G(alpha)i2 selectively potentiates 5-HT1A-mediated antidepressant effects. Proc Natl Acad Sci USA. 2010;107:11086-91.

59. Stewart A, Maity B, Wunsch AM, Meng F, Wu Q, Wemmie JA, et al. Regulator of Gprotein signaling 6 (RGS6) promotes anxiety and depression by attenuating serotonin-mediated activation of the $5-\mathrm{HT}(1 \mathrm{~A})$ receptor-adenylyl cyclase axis. FASEB J. 2014;28:1735-44.

60. Audo I, Bujakowska K, Orhan E, Poloschek CM, Defoort-Dhellemmes S, Drumare I, et al. Whole-exome sequencing identifies mutations in GPR179 leading to autosomal-recessive complete congenital stationary night blindness. Am J Hum Genet. 2012;90:321-30

61. Peachey NS, Ray TA, Florijn R, Rowe LB, Sjoerdsma T, Contreras-Alcantara S, et al GPR179 is required for depolarizing bipolar cell function and is mutated in autosomal-recessive complete congenital stationary night blindness. Am J Hum Genet. 2012;90:331-9.

62. Ray TA, Heath KM, Hasan N, Noel JM, Samuels IS, Martemyanov KA, et al. GPR179 is required for high sensitivity of the mGluR6 signaling cascade in depolarizing bipolar cells. J Neurosci. 2014;34:6334-43.

63. Sarria I, Orlandi C, McCall MA, Gregg RG, Martemyanov KA. Intermolecular interaction between anchoring subunits specify subcellular targeting and function of RGS proteins in retina ON-bipolar neurons. J Neurosci. 2016;36:2915-25.

64. Orlandi C, Cao Y, Martemyanov KA. Orphan receptor GPR179 forms macromolecular complexes with components of metabotropic signaling cascade in retina ON-bipolar neurons. Invest Ophthalmol Vis Sci. 2013;54:7153-61. 